\title{
Efficacy of natrium diclofenac gels application after odontectomy of lower third molar by assessment of swelling based on the level of alpha amylase and imunoglobulin-g: Research
}

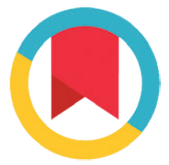

CrossMark

\author{
Sulfiana, ${ }^{1 *}$ Harmas Y. Yusuf, ${ }^{2}$ Lucky Riawan ${ }^{2}$
}

\section{Abstract}

Objective: The study was conducted on 60 patients determined with non-probability method using consecutive random sampling techniques according to the subject's order of arrival to the Outpatient of Oral and Maxillofacial Surgery Dental Hospital Padjajaran University for wisdom teeth odontectomy.

Material and Methods: Samples were divided into two groups, the treatment group (which was given diclofenac sodium gel) and the control group (which was not given diclofenac sodium gel). Initial data collection of facial dimensions and assessment of salivary alpha amylase levels were performed prior to odontectomy. Retrieval of data was carried out at 2 hours, 3 days and 7 days after the procedure of odontectomy under local anesthesia.

Result: No difference in swelling after odontectomy of the mandibular third molar after given the application of diclofenac sodium gel based with no given the application of diclofenac sodium gel based on imunoglobulin $\mathrm{G}$ levels in the impaction classification class la, lb, Ic, Ila, $\| \mathrm{lb}$, Ilc, with $p$ value $>0.05$.

Conclusion: there is a difference in swelling in the group given sodium diclofenac gel and not given sodium diclofenac gel based on alpha amylase levels in the classification.

Keywords: Diclofenac sodium gel, Imunoglobulin G, Odontectomy, Salivary alpha amylase, Swelling

Cite this Article: Sulfiana, Yusuf HY, Riawan L. 2021. Efficacy of natrium diclofenac gels application after odontectomy of lower third molar by assessment of swelling based on the level of alpha amylase and imunoglobulin-g: Research. Journal of Dentomaxillofacial Science 6(1): 22-26. DOl: $10.15562 /$ jdmfs.v6i1.1020

${ }^{1}$ Department of Oral and Maxillofacial Surgery, General Hospital Dr Hasan Sadikin, Bandung, Indonesia ${ }^{2}$ Department of Oral and Maxillofacial Surgery, Faculty of Dentistry, Padjajaran University, Bandung, Indonesia

*Correspondence to: Sulfiana, Department of Oral and Maxillofacial Surgery, General Hospital Dr Hasan Sadikin, Bandung, Indonesia sulfiana784@gmail.com

Received: 21 December 2019 Revised: 30 March 2020 Accepted: 17 March 2021 Available 0nline: 1 April 2021

\section{Introduction}

Odontectomy is the action of removing impacted teeth or partial eruptions with the stage of making a flap in the gingiva around the impacted tooth followed by removal of bone tissue that covers the teeth minimally and removal of teeth either intact or divided. This procedure can cause pain, inflammation including swelling, and trismus after surgery. ${ }^{1-3}$

Swelling can be seen with a change in the size of the face on the odontectomy side. Several things can be done to reduce the swelling and overcome the discomfort. One of them is the use of antiinflammatory drugs. ${ }^{4,5}$

Sodium diclofenac gel is a non-steroidal antiinflammatory (NSAID) which inhibits enzymes (COX) thereby inhibiting prostaglandin production which mediates the antipyretic, analgesic and anti-inflammatory effects so that it can relieve swelling. The most common side effect of oral diclofenac are gastritis, peptic ulcer, and depression of renal function. Due to some of these disadvantages diclofenac was developed in the direction of topical use including through the skin as an alternative solution. ${ }^{6,7}$
One indicator of the swelling process is the alpha amylase enzyme. Alpha amylase is a protein found in saliva and is a polysaccharide degradation enzyme used for evaluation of inflammation. ${ }^{3}$

Other biological markers that can be used are immunoglobulins including immunoglobulin G (Ig $\mathrm{G})$. Ig $\mathrm{G}$ is a multifunctional protein molecule that functions as an antibody. Apart from being an immune effector cell, the literature also explains the benefits of Ig $G$ in triggering pro-inflammatory responses to cellular and molecular antiinflammatory activity. ${ }^{8-10}$

\section{Material and Methods}

A total of 60 patients with impaction classification classes Ia, Ib, Ic, IIa, IIb, and IIc. This study was conducted in the Oral Surgery Department of the Dental and Oral Hospital of Padjajaran University in the Oral Surgery Outpatient Installation, Facial dimensions are measured before, 2 hours after odontectomy, three days after odontectomy and the seventh day after odontectomy. Alpha amylase was measured before, 2 hours after odontectomy, three days after odontectomy and the seventh day 
after odontectomy. Immunoglobulin G is measured 2 hours after odontectomy. Divided into 2 groups, namely group I (given sodium diclofenac gel) and group II (not given sodium diclofenac gel).

\section{Variables and data measurement}

One researcher was responsible for collecting data on the following variables: sex, facial dimension, alpha amylase and imunoglobulin. Measurement of facial dimensions (swelling) by measuring the distance of the original commissure to the tragus, tragus to mentale, and lateral chantus of the eye to the mandibular angle from the side to be carried out odontectomy. Figure 1A-figure 1C. The total of these measurements are recorded as face dimensions. ${ }^{10-12}$

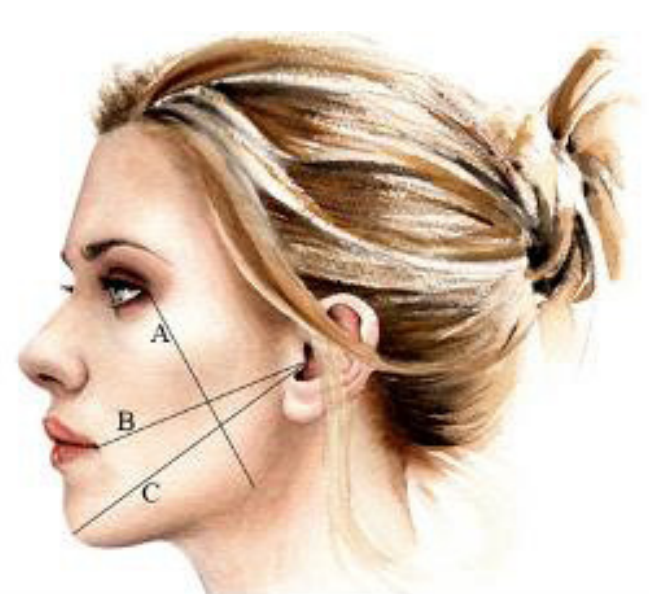

Figure 1 Measurement of swelling. A. Chantus of the eye lateral to the mandibular angle, B. Tragus to the original commissure, C. Tragus to mentale

\section{Sample collection}

The research subjects were taken from the age of subjects ranging from 18-30 years. Surgery on only one side of the face. The patient is not taking antibiotics, analgesics or anti-inflammatories before the procedure. Odontectomy is performed under local anesthesia. Post odontectomy given antibiotics and oral analgesics for 5 days.

\section{Statistical Analysis}

Data analysis includes descriptive analysis and $t$ test. Analysis of the research data with 95\% significance level of significance was determined based on $\mathrm{p}<0.05$. Data were analyzed using the Mega Start Excell program.

\section{Results}

Results in table 1, there were significant differences in swelling and alpha amylase levels $(\mathrm{p}<0.05)$ at 2 hours, three days post surgery and seven days post surgery, and there were no differences in immunoglobulin $G$ levels in the Ia class classification with significant $\mathrm{p}>0.05$.

Table 2 the results there are significant differences in swelling and alpha amylase levels in 2 hours post surgery, three days post surgery and seven days post surgery $(\mathrm{p}<0.05)$, and there are no differences in immunoglobulin $G$ levels in groups I and II.

Table 3, the results there are differences in swelling of 2 hours, three days post surgery and seven days after surgery and there are differences in alpha amylase levels at various days, and there is no difference in immunoglobulin $\mathrm{G}$ levels with $\mathrm{p}>$

Table 1 Differences in swelling, alpha amylase and immunoglobulin $\mathbf{G}$ in class la impaction classification

\begin{tabular}{lccc}
\hline \multirow{2}{*}{ Variable } & \multicolumn{2}{c}{ Classification of Class Ia Impaction } & \\
\cline { 2 - 3 } & Group I & Group II & P value \\
\hline Swelling & & & 0.39 \\
$\quad$ Pre Operation vs 2 hours Post Surgery & 0.56 & 0.60 & 0.00 \\
2 Hours Post Surgery vs. 3 days Post Surgery & 2.76 & 2.00 & 0.00 \\
3 Days Post Surgery vs. 7 days Post Surgery & 3.62 & 2.00 & 0.09 \\
Alpha Amylase & & & 0.00 \\
Pre Operation vs 2 hours Post Surgery & 9.80 & 8.00 & 0.00 \\
2 Hours Post Surgery vs. 3 days Post Surgery & 10.20 & 21.00 & 0.45 \\
3 Days Post Surgery vs. 7 days Post Surgery & 8.60 & 12.33 & 1.32 \\
Immunoglobulin G & 1.32 & & \\
\hline
\end{tabular}

*)paired t-test

$*$ group I (treatment)

${ }^{*}$ group II (control) 
Table 2 Differences in swelling, alpha amylase and immunoglobulin $\mathbf{G}$ in Class Ib impaction classification

\begin{tabular}{lccc}
\hline & \multicolumn{2}{c}{ Classification of Class Ib Impaction } & \\
\cline { 2 - 3 } Variable & Group I & Group II & P value \\
\hline Swelling & & & \\
$\quad$ Pre Operation vs 2 hours Post Surgery & 1.17 & 1.33 & 0.30 \\
2 Hours Post Surgery vs. 3 days Post Surgery & 3.37 & 0.50 & 0.00 \\
3 Days Post Surgery vs. 7 days Post Surgery & 4.78 & 0.83 & 0.00 \\
Alpha Amylase & & & \\
$\quad$ Pre Operation vs 2 hours Post Surgery & 9.17 & 7.00 & 0.08 \\
2 Hours Post Surgery vs. 3 days Post Surgery & 13.00 & 6.33 & 0.02 \\
3 Days Post Surgery vs. 7 days Post Surgery & 10.83 & 13.33 & 0.00 \\
Immunoglobulin G & 1.37 & 1.37 & 0.49 \\
\hline
\end{tabular}

$\left.{ }^{*}\right)$ paired t-test

${ }^{*}$ group I (treatment)

* group II (control)

Table 3 Differences in swelling, alpha amylase and immunoglobulin $\mathbf{G}$ in class Ic impaction classification

\begin{tabular}{lccc}
\hline & \multicolumn{2}{c}{ Classification of Class Ic Impaction } & \multirow{2}{*}{ P value } \\
\cline { 2 - 3 } Variable & Group I & Group II & \\
\hline Swelling & & & 0.35 \\
$\quad$ Pre Operation vs 2 hours Post Surgery & 1.38 & 1.50 & 0.00 \\
2 Hours Post Surgery vs. 3 days Post Surgery & 4.90 & 2.63 & 0.01 \\
3 Days Post Surgery vs. 7 days Post Surgery & 4.42 & 3.00 & 0.01 \\
Alpha Amylase & & & 0.02 \\
Pre Operation vs 2 hours Post Surgery & 15.33 & 9.25 & 0.01 \\
2 Hours Post Surgery vs. 3 days Post Surgery & 18.33 & 12.00 & 0.33 \\
3 Days Post Surgery vs. 7 days Post Surgery & 16.17 & 8.75 & 1.35 \\
Immunoglobulin G & 1.33 & & 0.33 \\
\hline
\end{tabular}

*)paired t-test

$*$ group I (treatment)

* group II (control)

Table 4 Differences in Swelling, Alpha Amylase and Immunoglobulin G in Class Ila Impaction Classification

\begin{tabular}{lccc}
\hline & \multicolumn{2}{c}{ Classification of Class Ila Impaction } & \multirow{2}{*}{ V value } \\
\cline { 2 - 3 } Variable & Group I & Group II & \\
Swelling & & & 0.00 \\
$\quad$ Pre Operation vs 2 hours Post Surgery & 0.88 & 4.03 & 0.04 \\
2 Hours Post Surgery vs. 3 days Post Surgery & 1.78 & 3.67 & 0.00 \\
3 Days Post Surgery vs. 7 days Post Surgery & 2.27 & 6.33 & 0.00 \\
Alpha Amylase & & 11.00 & 0.01 \\
Pre Operation vs 2 hours Post Surgery & 41.17 & 8.67 & 0.30 \\
2 Hours Post Surgery vs. 3 days Post Surgery & 61.17 & 24.00 & 0.28 \\
3 Days Post Surgery vs. 7 days Post Surgery & 26.67 & 1.32 & \\
Immunoglobulin G & 1.33 & & \\
\hline
\end{tabular}

$\left.{ }^{*}\right)$ paired t-test

* group I (treatment)

* group II (control) 
Table 5 Differences in swelling, alpha amylase and immunoglobulin $\mathbf{G}$ in class Illb impaction classification

\begin{tabular}{lccc}
\hline \multirow{2}{*}{ Variable } & \multicolumn{2}{c}{ Classification of Class Ilb Impaction } & \multirow{2}{*}{ P value } \\
\cline { 2 - 3 } Swelling & Group I & Group II & \\
$\quad$ Pre Operation vs 2 hours Post Surgery & 1.60 & 0.67 & 0.00 \\
2 Hours Post Surgery vs. 3 days Post Surgery & 3.90 & 5.83 & 0.03 \\
3 Days Post Surgery vs. 7 days Post Surgery & 4.18 & 3.83 & 0.35 \\
Alpha Amylase & & & 0.49 \\
Pre Operation vs 2 hours Post Surgery & $1 ., 25$ & 16.33 & 0.04 \\
2 Hours Post Surgery vs. 3 days Post Surgery & 11.75 & 15.00 & 0.00 \\
3 Days Post Surgery vs. 7 days Post Surgery & 25.75 & 11.00 & 0.33 \\
Immunoglobulin G & 1.34 & 1.32 & \\
\hline
\end{tabular}

*)paired t-test

* group I (treatment)

* group II (control)

Table 4 the results that there are differences in preoperative swelling and alpha amylase levels, 2 hours post surgery and three days post surgery. and there were no differences in immunoglobulin $\mathrm{G}$ levels in groups I and II.

Table 5 above that there was a significant difference in swelling and alpha amylase levels at 2 hours post surgery, three days post surgery ( $\mathrm{p}$ $<0.05$ ), and there were no differences in immunoglobulin G levels in groups I and II.

\section{Discussion}

This study found there were differences in swelling and alpha amylase levels in the class classification of class Ia, Ib, Ic at 2 hours, the third day and the seventh day post surgery and the class IIa impaction class classification, 2 hours, the third day after odontectomy, and on class IIb at 2 hours, the third day after odontectomy and class IIc impaction classification on the third and seventh day after odon-tectomy with $\mathrm{p}<0.05$ which means that there are differences in swelling and alpha amylase levels in the group given sodium diclofenac gel with those not given sodium diclofenac gel.

Inflammation is a normal response after trauma to the tissue. Inflammation begins to appear after odontectomy, reaches its peak on the third day, and begins to decrease until it returns to normal around the seventh day. Measures to control swelling can be done with thermal, physical (compression) and anti- inflammatory drugs. ${ }^{11-14}$

Diclofenac is an NSAID drug, used to relieve pain and inflammation. This test shows that sodium diclofenac gel has the effect of preventing facial swelling after odontectomy in various classifications of impaction.
In this study there was no significant difference in the value of immunoglobulin $G$ between the groups given sodium diclofenac gel and the groups not given sodium diclofenac gel in impaction classifications of class Ia, Ib, Ic, IIa, IIb and IIc.

\section{Conclusion}

This study shows that there is a difference in swelling in the group given sodium diclofenac gel and not given sodium diclofenac gel based on alpha amylase levels in the classification classification of class Ia, Ib, Ic, IIa, IIb, and IIc, so that sodium diclofenac gel can be an alternative to reduce post odontectomy swelling.

\section{Acknowledgment}

Thank you very much to Department of Oral and Maxillofacial Surgery, General Hospital Dr Hasan Sadikin and Faculty of Dentistry Padjadjaran University for the support of this research.

\section{Conflict of Interest}

The authors report no conflict of interest.

\section{References}

1. James R Hupp, Tucker MR, Ellis E, et al. Contemporary oral and maxillofacial surgery. 6th ed. United States of America: Mosby; 2014. p. 157- 167.

2. Rahayu S. Odontectomy, the management of impacted wisdom teeth. J WIDYA Kesehatan Lingkungan 2014;1: 81- 89. (In Indonesia)

3. Corrales AG, Compano CE, Castilo DG, et al. Relationship between salivary and postoperative swelling after the extraction of impacted lower third molars. Int J Oral \& Maxillofac Surg 2017;46: 243- 249. 
4. Juodzbalys G, Daugela P. Mandibular third molar impaction: review of literature and a proposal of a classification. J Oral Maxillofac Res 2013;4: e1.

5. Deliverska EG, Petkova M. Complications after extraction of impacted third molar- literature review. J IMAB 2016;22: 1202-1211.

6. da-Silva-Costa LF, Tiussi LD, Nascimento MS, et al. Diclofenac topical gel in excisional wounds maintain heal quality and reduce phlogistic signals1. Acta Cir Bras 2014;29: 328-333.

7. Purwanti T, Erawati T, Rosita N, et al. Release and penetration of sodium diclofenac SPAN 60 niosome system on the basis of the HPMC 4000 gel. J Pharma Scientia 2013;2: 1-12. (In Indonesia)

8. Nezlin R. Variety of immunoglobulin $\mathrm{g}$ functions. J Immunol Clin Res 2017;4: 1-3.

9. Aschermann S, Lux A, Baerenwaldt A, et al. The other side of immunoglobulin G: suppressor of inflammation. J Translational Immunol 2010;160: 161-167.

10. Ling XF, Heng TL, Bin-Mohammad AF. Early removal of asymptomatic mandibular third molar-is it safe? J Dentomaxillofac Sci 2017;2: 172-175.
11. Bansal N, Valiathan A, Bansal K et al. Management of multiple impacted teeth. Contemp Clin Dent 2012;3: 129-133.

12. Klongnoi B, Kaewpradub P, Boonsiriseth K, et al. Effect of single dose preoperative intramuscular dexamethasone injection on lower impacted third molar surgery. Int J Oral Maxillofac Surg 2012;41: 376-379.

13. Shimaa SA. Clinical evaluation of cox-2 inhibitor for management of post operative complication after odontectomy of impacted third molar. J Am Sci 2014;10: 60-63.

14. Blondeau F, Daniel NG. Extraction of impacted mandibular third molars: postoperative complication and their risk factors. J Can Dent Assoc 2007;73: 325.

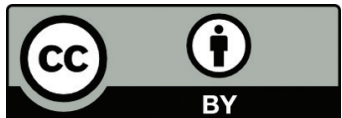

This work is licensed under a Creative Commons Attribution 